\title{
Development, direction, and damage limitation: Social learning in domestic fowl
}

\author{
CHRISTINE J. NICOL \\ University of Bristol, Bristol, England
}

\begin{abstract}
This review highlights two areas of particular interest in the study of social learning in fowl. First, the role of social learning in the development of feeding and foraging behavior in young chicks and older birds is described. The role of the hen as a demonstrator and possible teacher is considered, and the subsequent social influence of brood mates and other companions on food avoidance and food preference learning is discussed. Second, the way in which work on domestic fowl has contributed to an understanding of the importance of directed social learning is examined. The well-characterizedhierarchical social organization of small chicken flocks has been used to design studies which demonstrate that the probability of social transmission is strongly influenced by social relationships between birds. The practical implications of understanding the role of social learning in the spread of injurious behaviors in this economically important species are briefly considered.
\end{abstract}

Chickens were originally domesticated from the red junglefowl (Gallus gallus spadiceus), a harem-polygynous species that lives in flocks of 4 to 30 adults (Mench \& Keeling, 2001). Despite domestication over 8,000 years ago, the behavior of domestic birds living a feral existence is remarkably similar to that of their wild progenitors. In a study of domestic birds released onto a remote Scottish island, it was found that all the behavioral elements observed in junglefowl were still present in the behavioral repertoire of domesticated birds (Wood-Gush \& Duncan, 1976).

Under natural conditions, fowl live in brush and forest in small mixed-sex groups, guarded by a dominant cockerel (McBride, Parer, \& Foenander, 1969). Social facilitation of behavior within the group is notable, and behaviors such as foraging, dustbathing, preening, or resting are often performed at the same time by birds in close proximity (Lundberg, 2002). Birds within a group communicate with a diverse set of complex calls, postures, and displays (Wood-Gush, 1971). The fowl has a vocal repertoire of at least 31 different calls (Wood-Gush, 1971), many of which appear to transmit information about predator presence and type, or about food availability and quality (Evans \& Evans, 1999; Evans \& Marler, 1994). Other calls are associated with situations such as the thwarting of feeding or nesting behavior (Zimmerman \& Koene, 1998).

In a varied environment, domestic fowl select a mixed diet of seed, fruits, vegetation, and invertebrates. The

The support of the Biotechnology and Biological Research Council for my work on social learning in domestic fowl is gratefully acknowledged Bennett Galef and an anonymous reviewer provided helpful comments on earlier drafts of this paper. Correspondence should be addressed to C. J. Nicol, Department of Clinical Veterinary Science, Langford House, Langford, Bristol BS40 5DU, England (e-mail: c.j.nicol@bristol.ac.uk). chicks do not have an innate ability to recognize such a diverse array of food types and initially peck at food and nonfood items alike, and they have to learn which items are worthwhile to ingest (Hogan, 1984). The consequences of ingestion play little part in the initial development of food discrimination, so social learning is functionally of great importance at this time.

As these birds mature, their smell and taste perception is refined and they become active foragers. Semi-wild junglefowl spend over $90 \%$ of their active time eating, ground pecking, and scratching for food (Dawkins, 1989). This propensity to forage within a stable, communicative, interactive group provides an ideal environment for social learning about food. However, older birds appear to integrate information arising from observation of conspecifics with their own information about food palatability.

The first part of this review focuses on the changing ways in which social learning is used to acquire information about food palatability during the lifetime of a chicken. In early life, chicks are especially sensitive to social guidance about which foods they should and should not ingest. As these birds age, their developing cognitive abilities provide a basis for delayed social learning about food appearance and location. In the older birds, experience acquired via individual associative learning plays a more important role, but evidence that social learning interacts with innate predispositions (e.g., to avoid certain food colors) to modify feeding behavior is reviewed here as well.

The second part of this review considers how new behaviors are acquired in adult domestic fowl and, in particular, how social relationships between birds influence the probability of social transmission. In chickens, aggressive interactions between adult males and females are rare, and separate single-sex dominance hierarchies are formed in early life. Adult-female dominance hierar- 
chies can be extremely stable over time. Status is affected by individual physical characteristics, hormonal status, and recent individual experience of victory or defeat (Mench \& Keeling, 2001). Intriguingly, hens are also influenced by observation of agonistic interactions between flock mates. Hens will attack an unfamiliar hen if they have seen a flock mate defeat that stranger, but not if they have seen the stranger defeat the flock mate (Hogue, Beaugrand, \& Laguë, 1996). Affiliative behavior is also shown among hens, with preferences for particular others not necessarily dependent on social status (Mench \& Keeling, 2001). These social characteristics make chickens an ideal species in which to examine directed social learning.

\section{Social Transmission of Food Preferences}

Hen:chick interactions. The behavior of the hen is important in encouraging chicks to peck at edible items, because during the first few days of life, pecking behavior is not particularly sensitive to positive reinforcement from ingestion of feed and therefore provides little support for conventional associative learning.

Junglefowl hens attract their young to food with a complex behavioral display, consisting of staccato food calls and pecking movements directed toward food items on the ground (Sherry, 1977; Stokes, 1971). Hens give both more intense and longer food calls in the presence of high-quality food items (Moffatt \& Hogan, 1992). Similar maternal displays occur in hens of other Gallinaceous species, such as white-tailed ptarmigan (Lagopus leucurus), that emit unique vocalizations when specific, relatively high-protein, foods are encountered (Clarke, 1998).

The behavior of the hen attracts chicks to the area where the hen is feeding, with chicks responding more quickly to displays indicating high-quality food (Moffatt \& Hogan, 1992). Although it seems obvious that the mother must be a major influence on development of food preferences in the young, surprisingly few studies have examined the nature of this influence or compared the learning behavior of chicks exposed to alternative social demonstrators. An exception is to be found in the work by Gajdon (2001), who compared groups of hens and chicks when the hens had been trained to eat either red or green food in a test arena. The hens' food preferences were transferred to their chicks and were maintained even when the chicks were later tested separately from the hens. The exact mechanisms that support this type of social learning in chicks are not known, but clearly the hen's behavior functions to draw the chicks' attention to edible or profitable food sources.

Food calling in maternal hens is modulated by social context. The hen does not perform a food-calling display in a stereotyped and fixed fashion when she encounters a profitable food item. The sight of young chicks inhibits maternal feeding and prolongs display (Sherry, 1977), and in natural conditions, the maternal display of junglefowl hens is intensified when chicks move too far away or fail to respond (Stokes, 1971). Also, in experi- mental conditions, hens vocalize longer and give more food calls when chicks are visible but are physically separated from the hen than when the chicks are free to interact with the hen (Wauters, Richard-Yris, Pierre, Lunel, \& Richard, 1999); this suggests that hens are sensitive to the proximity and behavior of their chicks during the time that chicks are learning what to eat and what to avoid. It is interesting to consider whether this sensitivity is sufficient to attach the label "teaching" behavior to hens' maternal display.

One aspect of Caro and Hauser's (1992) definition of teaching was that teaching behavior should occur only in the presence of a naive observer and at some cost, or least without immediate benefit, to the teacher. Caro and Hauser further drew a distinction between fixed and flexible "teaching" behavior, arguing that without being sensitive to changes in offspring behavior, maternal behavior might vary rigidly as a function of time since parturition. To demonstrate flexible maternal behavior, it would be necessary to show that a mother's response could be adjusted in functionally relevant ways in response to the existing skill level of her offspring, rather than according to some more global cue such as offspring age. An experimental paradigm to do just this was designed by Nicol and Pope (1996). The aim of their experiment was to determine whether maternal display of broody domestic hens was modulated, not only by the sight and proximity of chicks, but also by an assessment of whether chicks had acquired relevant or correct information about the edibility of food items.

Twelve broody hens were housed together with their chicks, except during feeding sessions that occurred four times daily, when the hens and chicks were placed in separate feeding pens. The hens were trained that feed of one color was palatable and that feed of a different color was unpalatable. The chicks from each brood were divided into two groups of equal size and fed separately. One group of chicks received one dish of palatable and one dish of unpalatable feed, coded with the same colors that the hen had been trained on. The other group of chicks received one dish of palatable and one dish of unpalatable feed, coded with the opposite colors of those used with the hen, ensuring that the chicks in that group learned to feed on food of a color that their mother had been trained to avoid. In subsequent test sessions, each broody hen observed the feeding behavior of her two groups of chicks on alternate days, with color and order counterbalanced across hens.

Although there were no significant effects on the broody hens' vocalization, other aspects of the maternal display including food pecking, food dropping, and food scratching were significantly increased when the hens observed chicks that were making apparent errors. The intensity of the maternal display was increased, not in response to any actual chick disgust reaction to unpalatable food, but in response to the combined assessment of the hen of her chicks' feeding behavior and her own information about food palatability. Such intense displays increase the speed 
at which chicks approach the mother and attempt to peck at the food she is demonstrating (Moffatt \& Hogan, 1992). The results of Nicol and Pope's (1996) study suggest that intensity of maternal display may function not only to attract chicks to profitable food items, but also to redirect their attention away from harmful or nonprofitable items.

Interactions between young chicks. Under natural conditions, very young chicks direct most of their attention toward the hen. Maternal display appears to encourage chicks to peck more frequently at demonstrated items, and it may well be that the chick is hardwired to respond by increasing its own pecking in response to this. No work has been done to determine whether chicks are able to inhibit pecking at items that a hen avoids, and there are no anecdotal reports of such inhibitory behavior. There is, however, some evidence that chicks can inhibit pecking after observing deleterious experiences of their brood mates (Johnston, Burne, \& Rose, 1998). Such an ability would appear to confer an important advantage, but it is not a trait distributed widely throughout the animal kingdom. In Norway rats, for example, social learning does not lead directly to avoidance of potentially harmful foods (Galef, 1996).

Social learning of food avoidance is likely to depend on the balance of selective pressures varying as a function of the toxicity and frequency of encounter of potential poisons, and on the likelihood of social interaction during or after a harmful encounter. It is noteworthy, then, that day-old chicks avoid pecking at an aversive stimulus after observing the disgust responses of another chick (Johnston et al., 1998). Using a one-trial passive avoidance task, demonstrator chicks were presented with a bead coated in bitter-tasting methylanthranilate (MeA). Having pecked once at the bead, the demonstrator chicks showed a disgust reaction that included rapid head shaking, beak wiping, calling, and subsequent avoidance of similar beads. A marked effect of observation was found, with similar levels of pecking inhibition toward the beads shown by both the demonstrator and the observer chicks, that lasted at least $24 \mathrm{~h}$. In contrast, when the demonstrator chicks had pecked at a water-coated bead, or if the demonstrator chicks were trained out of sight of the observer chicks, there was no apparent avoidance of the beads by the observer chicks.

These results suggest that observational conditioning may be an important mechanism governing early acquisition of feed preferences in young chicks. It should be noted that the young chick is very different from the adult bird. Because the reward of food ingestion is not strongly involved in pecking motivation in juveniles (Hogan, 1984), chicks may be more attentive to behaviors of conspecifics, and less attentive to their own experiences of ingestion, than older birds. In addition, chicks may also react more to the general releasing features of stimuli than older birds do. For example, chicks but not adults will peck preferentially at stimuli that have been indicated by an automated moving arrowhead (Nicol \& Pope, 1992; Suboski \& Bartashunas, 1984). Such re- sults suggest that social learning in older birds will occur only in the presence of relatively complex or naturalistic stimuli and will be accompanied by an evaluation of individual experience.

Interactions between older chicks. After the first week of life, chicks tend to move away from their mother and explore on their own. At this time, brood mates become potential, although probably less accomplished, food discoverers than the hen. Correspondingly, social influences on feeding appear to shift from imprintingtype mechanisms toward more flexible forms of learning where both social transmission and individual associative learning are involved. Gajdon, Hungerbühler, and Stauffacher (2001) studied 2- to 8-day old chicks kept in small groups. The aim of the study was to determine whether groups of chicks containing a knowledgeable demonstrator would develop more successful foraging behavior than would groups of chicks with a naive demonstrator, and whether both groups would develop similar food preferences. A test arena was constructed where caches of red or green food were hidden and the presence of caches was indicated by either red or green threedimensional markers. Demonstrator chicks either were trained to feed from one of the two types of marked locations, or were naive. After training, each demonstrator was released into the test arena with a group of 4 naive observers. The total amounts of food consumed varied among treatments. Both on trials when their demonstrator was foraging with them, and on subsequent trials when they foraged alone, chicks paired with trained demonstrators consumed more food than chicks paired with naive demonstrators. It is difficult to establish the mechanisms of social transmission in experiments if a demonstrator is free to interact with observers. In a second experiment, Gajdon et al. introduced a demonstrator compartment into the test arena to examine the effects of access to a demonstrator on the behavior of observer chicks.

Demonstrators were trained to eat red food next to a red cache marker. Two observation conditions were compared: a restricted condition, where observers could watch a demonstrator through a Perspex screen, and an unrestricted condition, where observers could enter the compartment and eat with the demonstrator. After $10 \mathrm{~min}$, the demonstrators were removed from the test arena, and the observer chicks were free to forage for food. No significant difference was found in the time taken for chicks from the different groups to find food, and all chicks found and ate more red food than green, even though green food was generally preferred in Experiment 1 . The preference for red food shows that chicks can learn by visual observation, in the absence of direct contact with a demonstrator either during the demonstration session or during the foraging test session. However, the restricted condition resulted in less successful foraging according to some measures. Some groups of birds from the restricted condition were never successful at the foraging task, and other groups showed longer latencies to find food than did groups from the unrestricted condition. 
Interactions between juvenile birds. Older gallinaceous birds feed gregariously, providing a good model for examining social learning of food preferences. At about Day 11 of life, chicks show a sudden peak in movement out of sight of the mother (Vallortigara, Andrew, Sertori, \& Regolin, 1997) and a similarly timed viewing bias toward the left eye, resulting in an almost exclusive involvement of the right hemisphere in visual processing (Dharmaretnam \& Andrew, 1994). Experience of the disappearance and reappearance of objects during this sensitive phase for the development of spatial memory is crucial. Without such experience, chicks are significantly hampered in their ability to remember the location of hidden objects (Freire, Cheng, \& Nicol, 2004; Freire \& Nicol, 1999). Development of spatial memory at this age enables chicks to forage more effectively and may be essential for effective social learning based on local or stimulus enhancement, particularly when there is a significant delay between the demonstration and the chance to respond.

McQuoid and Galef (1992) showed that junglefowl chicks 21-28 days old were attracted to particular marked feeding dishes or to particular pen locations $48 \mathrm{~h}$ after they had observed conspecifics feeding from the same type of dish or in the same location. When observers were unrewarded in their foraging behavior during test sessions, only some birds pecked, and those that did peck did so for only a few seconds. However, when food rewards were introduced into test sessions, observers directed sustained pecking to sites where they had previously observed demonstrators feeding, even though equally rewarding, but nondemonstrated, sites were also available. Both prior observation of a demonstrator and reward during the test procedure influenced the social transmission of feeding preferences in these older chicks, confirming that interactions between stimulus enhancement and individual associative learning occur.

Similar effects were observed when, rather than observing live demonstrators, junglefowl chicks were exposed to video images of demonstrators feeding from marked bowls. Social learning from the video images was increased when both visual and auditory information were available and when the demonstrators were filmed feeding from the bowl rather than being active elsewhere or being inactive (McQuoid \& Galef, 1993). Furthermore, social learning was not significantly disrupted by allowing birds to feed during video observation sessions (McQuoid \& Galef, 1994).

It was not an aim of these experiments to determine whether the moving images of conspecifics were perceived as equivalent to real birds, and McQuoid and Galef (1993) suggested that any vertical movement in the vicinity of a food dish might be as effective as the sight of a feeding conspecific in influencing feed preferences. Subsequent work on perception of video images by domestic fowl has shown that complex video images are not perceived as equivalent to real stimuli, and generalization during probe trials from video images to real stimuli or from real stim- uli to video images is poor. However, certain features of video images, such as color, are perceived as equivalent to the real thing, and birds will then generalize between media (Patterson-Kane, Nicol, Foster, \& Temple, 1997).

In a recent experiment, Sherwin, Heyes, and Nicol (2002) examined the extent to which social learning influenced formation of food preferences and aversions in adult 9-week-old laying hens. The aim of Sherwin et al.'s first experiment was to determine whether observer hens could learn to avoid pecking at a colored food that elicited a "disgust" reaction in a conspecific. A circular apparatus was designed that allowed 8 observers at one time to see the feeding behavior of a demonstrator placed in the center of the apparatus. In total, 32 observers saw demonstrators exhibit "disgust" reactions to unpalatable food, and 32 observers saw demonstrators eat normal food. Immediately after the observation sessions, observers were separated visually from each other and given two bowls of palatable colored feed, with one of the colors matching that just demonstrated.

During the observation sessions, all the demonstrators pecked at the feed, but the amount of food that they ingested was highly variable between demonstrators, and there were no significant treatment effects on pecking behavior. However, the demonstrators given unpalatable feed performed much beak wiping, a behavior that was seen rarely in demonstrators given standard feed, and they also performed twice as many head shakes as did the demonstrators given standard feed. Despite such clear differences in demonstrator behavior, the observer hens showed no avoidance of the colored food that had previously elicited a disgust reaction in their demonstrators. This result contrasts with that of Johnston et al. (1998) in a way that may somehow be related to age change. Possibly, young chicks, while developing an overall framework for classifying particles as edible or inedible, are sensitive to the consequences of the feeding behavior of others, and this sensitivity is reduced as the chick matures and the consequences of ingestion become integrated via individual associative learning. Alternatively, information available to observers differed between the experiments of Sherwin et al. (2002) and Johnston et al. The chicks used as demonstrators by Johnston et al. showed a disgust reaction accompanied by inhibition of pecking. In contrast, the adult hens used as demonstrators by Sherwin et al. showed a disgust reaction accompanied by continued pecking at the feed, thus providing potentially conflicting information.

In a second experiment, using the same apparatus, Sherwin et al. (2002) turned their attention to a study of whether social learning facilitated acquisition of preferences for different-colored foods. In this experiment, observers saw demonstrators not feeding, feeding on normal food, or feeding on "highly palatable" feed. There were no treatment effects on total amount of food consumed by the observers during the test. However, there was a positive correlation between the pecking rate of the demonstrators and the proportion of feed of the 
demonstrated color eaten by their respective observers. When this effect was examined more closely, it was apparent that there was an interaction with actual food color. The effect of a highly palatable demonstration induced birds to eat red food, which they otherwise tended to avoid. The interaction between observational experience and food color suggests that social learning in chickens might be important in overcoming unlearned aversions to particular colors that tend to signal unpalatability in nature (Guilford \& Rowe, 1996).

\section{Acquisition of New Skills by Adult Hens}

The possibility that domestic fowl might learn new responses socially was first examined by Cronhelm (1970). She provided evidence that observation of a trained demonstrator facilitated acquisition of an instrumental discrimination task in domestic chicks, but interpretation was difficult because the learning times of observers were compared directly with those of demonstrators, even though the observers were given more time to adapt to the experimental situation.

Johnson, Hamm, and Leahey (1986) studied acquisition of a simple instrumental keypeck response in adult chickens. Chickens that had observed a demonstrator responded earlier and more frequently on a subsequent autoshaping test than did chickens that had only observed correlations between keylight and food hopper operation or chickens that had had no observational experience. However, Johnson et al.'s (1986) experiment did not include a control for the simple presence of another chicken during observation sessions. Fear reduction resulting from the presence of a conspecific may have increased observer attention to keylights during the observation sessions or may have facilitated performance during the autoshaping test. Rigorous experimental design is needed to ensure a true demonstration of social learning, rather than an artefact due to some more general process (Zentall \& Galef, 1988).

The duplicate-cage procedure has been the most widely used method of investigating social acquisition of new skills in the laboratory. Nicol and Pope (1992) used this method to investigate social influences on acquisition of discriminatory keypecking in adult hens. Demonstrator hens were pretrained to peck one of two differently colored keys to obtain access to a food hopper. Observers were randomly allocated to conditions where the response chamber was occupied by a trained demonstrator, an untrained bird, or, to control for the effects of mere social presence, no bird at all. During the test phase, birds that had observed a trained demonstrator spent more time facing the keys, performed more keypecks and showed a significant bias toward pecking the same color key as that pecked by their respective demonstrators.

In a second experiment with the same procedure and apparatus, effects of observing a live, trained demonstrator were compared with those of observing an artificial rod "pecking" at a key and opening the door to the food hopper. In subsequent tests, birds that had observed rod pecking failed to peck at the keys when placed in the response chamber, whereas birds that had observed live demonstrators pecked at the keys and again showed a significant bias toward pecking the same color key as that pecked by their respective demonstrators. The results also showed that the presence of an untrained bird in the response chamber during observation sessions had no significant effect on response acquisition. Thus, the results cannot be explained by postulating a simple decrease in isolation-induced fear or by a similar process. The fact that the artificial rod was unsuccessful in inducing keypecking in observers shows that something about the behavior of the demonstrators was important in facilitating response acquisition in observers. Candidate mechanisms might be stimulus enhancement, observational conditioning, or imitation.

In an attempt to ensure the external validity of the laboratory-based studies, rather than pursue investigations into the mechanisms of social learning, Nicol and Pope $(1993,1994)$ turned their attention to contextual factors influencing social learning in adult laying hens. One feature of the classic experimental procedure is to deprive both demonstrator and observer animals of food before both observation and test sessions. The rationale for depriving observers is that motivational state determines the stimuli to which animals will attend (Dorrance \& Zentall, 2001). However, in a social learning context, food deprivation could cause a bird to attend more to the food itself than to the method being used to obtain that food. If so, food deprivation might actually be counterproductive. Alternatively, if food deprivation is essential for response acquisition, it would suggest that social learning may be relatively rare under natural conditions, where background motivational factors are not controlled.

To examine these issues, Nicol and Pope (1993) compared the behavior and performance of food-deprived and nondeprived observers in a duplicate-cage procedure. As in the previous experiment, birds paired with untrained demonstrators during the observation session made almost no keypecks when placed in the response chamber. The behavior of birds paired with trained demonstrators was then examined. It was found that nondeprived birds performed more pecks to the food hopper and showed a greater bias toward the key that their demonstrator had pecked than did birds that had been deprived of food for $4 \mathrm{~h}$ during observation sessions. The overall results suggested that food deprivation before observation sessions had a mild inhibitory effect on subsequent response of hens, possibly because nondeprived birds were more attentive to details of their demonstrators' behavior.

In general, the acquisition of environmental information obtained through exploration, sampling, and vigilance is increased under conditions of satiation (Inglis \& Ferguson, 1986; Krebs, 1980). This study suggests the same may be true for the social acquisition of information.

It is worth considering other ways in which the traditional duplicate cage procedure may or may not facili- 
tate social learning in domestic fowl. Separation of demonstrator and observer by a wire-mesh or Plexiglas partition during training is clearly useful. Despite the fact that removal of a partition improves social learning in marmosets, thereby allowing observers to gain a better view of the demonstration (Caldwell \& Whiten, 2003), the same does not appear to be the case for hens. In an experiment where the partition separating demonstrator and observer hens was removed, thus allowing small groups of observers to interact more closely with a trained demonstrator in the response chamber, the response rate of demonstrators declined dramatically. Some demonstrators attempted to defend the key area and threatened observers. Others were rapidly displaced by dominant scroungers (Barnard \& Sibly, 1981) that were attracted by the initial availability of food (Nicol \& Pope, 1999).

It has been implicitly assumed in most experiments on social learning in domestic fowl that vision is the sense most likely to mediate the transfer of information. Birds have well-developed color vision and good visual acuity. Thus, the assumption may be well founded, although it is worth noting that the auditory and olfactory senses of birds are more sensitive than is often realized. Also, little account is taken in most experiments of the ways in which bird vision differs from our own. For example, Dawkins (2002) showed that hens view distant objects laterally, but closer objects frontally. Birds' ability to see in the ultraviolet spectrum, and their very limited eye movements, can affect their behavior in experimental settings. However, it is birds' visual responses to novelty that are most relevant in the context of social learning. Many birds have asymmetries in eye function, and it has been shown that domestic fowl use the left eye preferentially for viewing novel objects (Dharmaretnam \& Andrew, 1994; Vallortigara \& Andrew, 1991). In addition, the retina of domestic fowl may be composed of compartmentalized, specialized areas, suggesting that the swinging movements of the head made by hens when they encounter novel objects may be designed to bring the object under the scrutiny of the most effective part of the retina (Dawkins, 2002). Aspects of the duplicate cage procedure commonly used in laboratory experiments on social learning may not allow birds to express their full range of investigative behaviors.

\section{Directed Social Learning}

An assumption behind some theoretical models of social learning is that social interactions occur at random within the population, and that social transmission probabilities between all pairs of animals are equal (CoussiKorbel \& Fragaszy, 1995). In reality, social learning is likely to be influenced by factors that produce biased transmission of traits through a population. Observers that use cues about demonstrators to choose which demonstrator to attend to will provide a source of indirect bias in transmission probability (Boyd \& Richerson, 1985). The term "directed social learning" has also been used to describe how social transmission probabilities are influenced by the social structure of the group, resulting in uneven transmission of information or skills through the group (Coussi-Korbel \& Fragaszy 1995; Laland, Richerson, \& Boyd, 1996). Differences in the extent to which naive individuals are able to approach more skilled individuals, and differences in attentiveness to particular others are likely to result in heterogeneity between group members in the acquisition of new skills and information (Fragaszy \& Visalberghi, 1996). Horizontal transmission between animals of the same age is thought to be adaptive when transmitted information is of transient value, as when different foraging strategies are exploited in response to temporary local variations in the environment (Laland et al., 1996). However, even among groups of animals of similar age or experience, some individuals may be more salient or influential demonstrators than others even if there are no differences in their levels of skill, performance rates or values as a predictor of reward.

When studying small flocks of laying hens, Nicol and Pope (1994) found that facilitation of social learning of a keypeck response to obtain food was greater when a dominant hen was used as a demonstrator than when a subordinate hen was so used. In Nicol and Pope's (1994) study, 12 flocks of 8 laying hens were observed during a 2 -week period before the social learning experiment began, all dyadic agonistic encounters were recorded, and a dominance rank order for each flock was constructed. Flocks were then randomly allocated to one of four demonstrator treatments that differed in the type of demonstrator selected: (1) the most dominant member of each group selected as demonstrators, (2) the most subordinate member of each group selected as demonstrators, (3) unfamiliar birds from a different population of laying hens, of unknown social rank, selected as demonstrators, or (4) no demonstrator. Although there were no significant differences in the performance characteristics of the different demonstrators, most correct keypecks were made by observers that had seen dominant demonstrators. One possible reason for the greater effectiveness of dominant hens might be that they simply provide a more striking or noticeable presence during the performance of specific behaviors. For example, dominant birds might be bigger, adopt a taller body posture, or peck with greater force. However, this line of reasoning was not supported by the inclusion, in a second experiment (Nicol \& Pope, 1999), of some flocks exposed to trained cockerels as demonstrators. Despite the fact that the cockerels were larger, socially dominant to the hens, and appeared to peck the key more forcefully, exposure to the cockerels resulted in little social learning in the hens, and all types of pecking were low when the observers that had seen cockerels were tested in the response chamber.

An alternative explanation of the greater effectiveness of dominant hens as demonstrators is that dominance may be a correlate of some other indicator of quality. Dominant birds might receive more attention from con- 
specifics because of their success in some other domain, rather than because of their social position per se. In red junglefowl, dominant hens have greater lifetime reproductive success than subordinates do (Collias, Collias, \& Jennrich, 1994), and it may be that, as either a cause or an effect of their social position, dominant hens are more successful foragers than subordinates are.

The influence of foraging success as a direct cue was examined by Nicol and Pope (1999) in an experiment where prior foraging success of demonstrators was manipulated in their home pens. In two flocks of birds, the most dominant bird was selected to be a "successful" forager, and the most subordinate bird was selected to be an unsuccessful forager. In two further flocks, the link between foraging success and dominance status was reversed. Foraging success was manipulated by simultaneously providing, in view of the other members of the group, the dominant and subordinate bird from each flock with a dish filled with wood shavings. The dish of the successful bird contained highly attractive hidden feed items such as mealworms and whole wheat grains. The dish of the unsuccessful bird did not contain these items. However, in subsequent keypecking tests, no effects of manipulating prior foraging success of birds was found on their salience as demonstrators. The failure of the manipulation of prior foraging success suggests that although birds may pay selective attention to birds that appear to be highly successful foragers (Sherwin et al., 2002), they do not appear to generalize the association and pay those same birds greater attention in a different foraging context.

In a similar investigation of links between dominance and foraging success, Pfeffer, Fritz, and Kotrschal (2002) determined whether dominance in greylag geese (Anser anser) was associated with a real (rather than experimentally manipulated) tendency to acquire new food-finding behaviors. Pfeffer et al. examined associations between tendency to remove food container lids in a test given at 6 weeks of age (innovative tendency), success during a competitive foraging task (a measure of dominance), and fecal levels of corticosterone and testosterone metabolites (indicators of physiological stress and coping ability). Dominance was not associated with either tendency to innovate or with physiological status. It was, however, observed that birds with low fecal-corticosterone metabolite levels at 2 weeks of age were significantly less likely to learn to remove lids from the food containers than birds with higher corticosterone-metabolite concentrations.

The authors suggested that young birds with the higher concentrations of corticosterone might be more responsive to environmental stimuli, and that becoming an innovator may be contingent upon individual "coping" style. A coping style was defined as a set of stable and consistent behavioral and physiological responses that predicts how an individual reacts to challenge, irrespective of sex or motivational state (see Benus, Koolhaas, \& van Oortmerssen, 1987). To conclude that innovation is associated with coping style, it would be necessary to demonstrate high intraindividual correlations in physiological measures taken repeatedly over time.

It remains frustratingly unclear why dominant hens are more effective demonstrators than their subordinates. One factor that may be partially correlated with dominance in hens is aggressiveness. Although cockerels are socially dominant, they tend to engage in fewer agonistic interactions with hens than do other hens. In contrast, dominant hens may attract continuous attention from subordinates that are attempting to avoid situations that might result in threat, aggression, or attack from dominants. The extent to which aggressiveness attracts the attention of conspecifics remains to be tested.

Directed social learning can arise from sources other than dominance (Reader \& Laland, 1999). Familiarity with the demonstrator is another social factor that can lead to unequal social transmission probabilities within a group. Individuals from many species, including domestic fowl (Dawkins, 1982; Mench \& Keeling, 2001), associate preferentially with familiar conspecifics, making it possible that such individuals may also be more preferred or more effective demonstrators for social learning. Swaney, Kendal, Capon, Brown, and Laland (2001) found that guppies (Poecilia reticulata) learned a route to a food source more quickly when the trained demonstrator fish was familiar than when it was unfamiliar. Benskin, Mann, Lachlan, and Slater (2002) found that male zebra finches (Taeniopygia guttata) exposed to familiar and unfamiliar demonstrators preferred the food hopper from which the familiar demonstrator had fed. Nicol and Pope (1994) found that, although the performance of hens that had observed unfamiliar demonstrators was slightly reduced compared with that of hens that had observed familiar dominant demonstrators, it was not significantly different from that of hens that had observed familiar subordinate demonstrators. Again, for laying hens, we are drawn to the possibility that they attend most to those individuals who offer the greatest potential threat.

Relatedness between parent and offspring might, most often, be thought to support social learning, particularly if the parent takes active steps to facilitate skill acquisition (see, e.g., Nicol \& Pope, 1996). However, Hatch and Lefebvre (1997) found a slight tendency for juvenile ring doves to learn more about a novel foraging technique from unrelated but familiar adults than from their fathers, possibly because in this case, greater parental tolerance encouraged scrounging and inhibited social learning. The influence of relatedness on social learning in fowl has been examined only in the context of the transmission of feeding preferences, and not in the context of the acquisition of novel traits or behaviors.

\section{Applications}

Many millions of chickens are kept throughout the world for egg production. Laying hens are particularly prone to feather pecking and cannibalism, injurious behaviors that are near ubiquitous when hens are housed in 
flocks of many thousands. Feather pecking and cannibalism are not aggressive behaviors, but forms of redirected foraging or dustbathing (Savory, 1995). The economic costs associated with feather pecking are significant, and the birds' welfare is seriously compromised. Outbreaks of feather pecking are sporadic and unpredictable. However, once the behavior arises within a flock, it often spreads rapidly, and social learning may play a part in its transmission (Nicol, 1995).

Zeltner, Klein, and Huber-Eicher (2000) investigated the possibility of social transmission of feather pecking by adding either pecking or nonpecking demonstrators to groups of 4-week-old chicks. Clear differences in rate of feather pecking were observed, with birds exposed to pecking demonstrators subsequently exhibiting higher rates of feather pecking and lower levels of foraging behavior than those of birds exposed to nonpecking demonstrators. The results suggest that feather pecking can be triggered by the observation of others, although the possibility that observers responded directly to plumage deterioration in conspecifics pecked by demonstrators cannot be excluded in this study.

Sherwin, Heyes, and Nicol (2004) have examined whether social transmission of feather pecking occurred when feather-pecking and naive birds were in only indirect visual or auditory contact. Groups of laying hen chicks were housed adjacent to older birds that showed either no feather pecking or mild feather pecking behavior. Half of all the naive groups of chicks were separated from the demonstrator groups by clear partitions, and half were separated by opaque partitions. Despite a housing period that lasted 20 weeks, no significant differences in feather pecking behavior were found in observer groups exposed to different treatment conditions. However, birds that had observed feather-pecking demonstrators through the transparent partition performed more environmental pecking than did any other group. Visual observation of feather pecking therefore increased observer pecking motivation, but observers did not direct their pecking to the same target as did demonstrators. The results could be explained as a form of social facilitation without any stimulus enhancement. If so, under a different set of environmental conditions, high levels of ground pecking by demonstrators might stimulate feather pecking among observers.

Cannibalism is often directed to body parts that are not part of the normal pecking repertoire, so social learning via stimulus enhancement might be relevant in the spread of this behavior. Cloutier, Newberry, Honda, and Alldredge (2002) devised a test of cannibalism which involved piercing a transparent membrane to access a pot of chicken blood. They found that tendency to peck or pierce the membrane was significantly associated with observation of a pretrained demonstrator. Despite this, the cannibalistic-type behavior studied did not generalize toward real birds in the home pen, supporting the idea that the observers' attention was focused on the fine details of the membrane-covered pots. Stimulus enhance- ment was therefore thought to be important in the development of the behavior. Cloutier et al. speculated whether observational conditioning might also have played a role, with feeding behavior of the demonstrators acting as a secondary reinforcer.

The tendency to feather peck appears to be so ingrained in domestic fowl that it may not be possible to eliminate the behavior through genetic selection or environmental management. If further work reveals that social learning is involved in transmission of these injurious behaviors, then consideration should be given to the use of visual partitions to reduce the chances of observational learning.

\section{Conclusion}

Studies in fowl have revealed that the benefits of social learning change across the life span as different foraging challenges emerge. In young birds, social learning is the primary method used to establish food preferences. In older birds, contextual factors, such as social dominance and stimulus color, interact with social learning to guide the development of new food preferences and the acquisition of new traits.

The domestic chicken is likely to provide a useful model for further work on the developmental, neurological, and social factors underpinning social learning. Precocial chicks hatch with well-developed brains and rapidly learn a great deal about their environment. Maternal and food recognition learning have been particularly well studied (e.g., Bateson, 1981; Hogan, 1984). Knowledge about neural substrates and mechanisms underpinning such learning in chicks is increasing rapidly (Gibbs, Andrew, \& Ng, 2003; McCabe, Horn, \& Kendrick, 2001), and experience-delineated developmental stages in learning are increasingly well-defined (Freire et al., 2004). Social learning is an important part of early chick development, and a greater understanding of the relationship between chick social learning and stage of development is emerging. This could provide the foundation for future comparative studies of the neurological bases of associative and nonassociative learning processes in a functionally relevant context.

The complex but well-characterized suite of behaviors exhibited by maternal hens during the period when their chicks are learning to discriminate food from nonfood items provides an ideal model for functional studies of the costs and benefits associated with animal teaching. The paucity of well-controlled experiments on animal teaching may in part be related to the difficulty of independently manipulating maternal and offspring experience in many species. Domestic fowl provide an ideal study species in this respect. Chicks will feed readily in the absence of the hen, but the nature of their feed intake and their longer term feed preferences are strongly influenced by the hen's behavior in ways that we are only beginning to understand.

The clear hierarchical social structure found within small flocks of fowl permits further study of the influence of factors such as age, aggressiveness, dominance, for- 
aging success, and reproductive success on the probability of social transmission of preferences and new behaviors. To complete the loop, studies that examine whether social learning can improve foraging success and influence a bird's social status are needed.

\section{REFERENCES}

BARNARD, C. J., \& SiBly, R. M. (1981). Producers and scroungers-a general model and its application to captive flocks of house sparrows. Animal Behaviour, 29, 543-550.

BATESON, P. (1981). Ontogeny of behaviour. British Medical Bulletin, 37, 159-164.

Benskin, C. M. H., Mann, N. I., Lachlan, R. F., \& Slater, P. J. B. (2002). Social learning directs feeding preferences in the zebra finch Taeniopygia guttata. Animal Behaviour, 64, 823-828.

Benus, R. F., KoolhaAs, J. M., \& VAn Oortme Rssen, G. A. (1987). Individual differences in behavioural reaction to a changing environment in mice and rats. Behaviour, 100, 105-122.

BOYD, R., \& RICHERSON, P. J. (1985). Culture and evolutionary process. Chicago: University of Chicago Press.

CAldWell, C. A., \& Whiten, A. (2003). Scrounging facilitates social learning in common marmosets, Callithrix jaccus. Animal Behaviour, 65, 1085-1092.

CARO, T. M., \& HAUSER, M. D. (1992). Is there teaching in nonhuman animals? Quarterly Review of Biology, 67, 151-174.

Clarke, J. A. (1998). Social transmission in the development of avian foraging behaviour: How do white-tailed ptarmigan (Lagopus leucurus) chicks learn what to eat? [Abstract]. In G. Fiorito (Ed.), Social learning and cultural transmission: From invertebrates to great apes and humans. Towards a biological synthesis (p. 74). Napoli Social Learning Conference, Naples, Italy.

Cloutier, S., Newberry, R. C., Honda, K., \& Alldredge, J. R. (2002). Cannibalistic behaviour spread by social learning. Animal Behaviour, 63, 1153-1162.

Collias, N. E., Collias, E. C., \& Jennrich, R. I. (1994). Dominant red junglefowlhens in an unconfined flock rear the most young over their lifetime. Auk, 111, 863-872.

Coussi-Korbel, S., \& Fragaszy, D. M. (1995). On the relation between social dynamics and social learning. Animal Behaviour, 50, 1441-1443.

Cronhelm, E. (1970). Perceptual factors and observational learning in the behavioral development of young chicks. In J. H. Crook (Ed.), Social behaviour in birds and mammals: Essays on the social ethology of animals and man (pp. 393-439). New York: Academic Press.

DAWKINS, M. S. (1982). Elusive concept of preferred group size in domestic hens. Applied Animal Ethology, 8, 365-375.

DAWKINS, M. S. (1989). Time budgets in red junglefowl as a baseline for the assessment of welfare in domestic fowl. Applied Animal Behaviour Science, 24, 77-80.

DAWKINS, M. S. (2002). What are birds looking at? Head movements and eye use in chickens. Animal Behaviour, 63, 991-998.

Dharmaretnam, M., \& Andrew, R. J. (1994). Age- and stimulusspecific use of right and left eyes by the domestic chick. Animal Behaviour, 48, 1395-1406.

DORRANCE, B. R., \& ZENTALL, T. R. (2001). Imitative learning in Japanese quail (Coturnix japonica) depends on the motivational state of the observer quail at the time of observation. Journal of Comparative Psychology, 115, 62-67.

Evans, C. S., \& Evans, L. (1999). Chicken food calls are functionally referential. Animal Behaviour, 58, 307-319.

EVANS, C. S., \& MARLER, P. (1994). Food calling and audience effects in male chickens Gallus gallus: Their relationship to food availability, courtship and social facilitation. Animal Behaviour, 47, 11591170

FrAgASZY, D. M., \& VisAlberghi, E. (1996). Social learning in monkeys: Primate "primacy" reconsidered. In C. M. Heyes \& B. G. Galef, Jr. (Eds.), Social learning in animals: The roots of culture (pp. 6584). San Diego: Academic Press.
Freire, R., ChenG, H.-W., \& NiCOL, C. J. (2004). Development of spatial memory in occlusion-experienced domestic chicks. Animal Behaviour, 67, 141-150.

FREIRE, R., \& NICOL, C. J. (1999). Effect of experience of occlusion events on the domestic chick's strategy for locating a concealed imprinting object. Animal Behaviour, 58, 593-599.

GAJDON, G. K. (2001). Social modification of early foraging in domestic chickens. Unpublished PhD thesis, University of Zurich.

Gajdon, G. K., Hungerbuhler, N., \& Stauffacher, M. (2001). Social influence on early foraging of domestic chicks (Gallus gallus) in a near-to-nature procedure. Ethology, 107, 913-937.

GALEF, B. G., JR. (1996). Social enhancement of food preferences in Norway rats: A brief review. In C. M. Heyes \& B. G. Galef, Jr. (Eds.), Social learning in animals: The roots of culture (pp. 49-64). London: Academic Press.

GibBs, M. E., ANDREw, R. J., \& NG, K. T. (2003). Hemispheric lateralization of memory stages for discriminated avoidance learning in the chick. Behavioural Brain Research, 139, 157-165.

GUILFORD, T., \& ROWE, C. (1996). Unpalatable evolutionary principles. Nature, 382, 667-668.

HAtch, K. K., \& LefebVRe, L. (1997). Does father know best? Social learning from kin and non-kin juvenile ringdoves. Behavioral Processes, 41, 1-10.

Hogan, J. A. (1984). Pecking and feeding in chicks. Learning \& Motivation, 15, 360-376.

Hogue, M.-E., Beaugrand, J. P., \& LAgu , P. C. (1996). Coherent use of information by hens observing their former dominant defeating or being defeated by a stranger. Behavioural Processes, 38, 241-252.

INGLIS, I. R., \& FERGUSON, N. J. K. (1986). Starlings search for food rather than eat freely available, identical food. Animal Behaviour, 34, 614-617.

Johnson, S. B., HAMm, R. J., \& LEAHEY, T. H. (1986). Observational learning in Gallus gallus domesticus with and without a conspecific model. Bulletin of the Psychonomic Society, 24, 237-239.

Johnston, A. N. B., Burne, T. H. J., \& Rose, S. P. R. (1998). Observational learning in day-old chicks using a one-trial passive avoidance learning paradigm. Animal Behaviour, 56, 1347-1353.

KREBS, J. R. (1980). Optimal foraging, predation risk and territory defence. Ardea, 68, 83-90.

LALAND, K. N., RicheRSON, P. J., \& BOyD, R. (1996). Developing a theory of animal social learning. In C. M. Heyes \& B. G. Galef, Jr. (Eds.), Social learning in animals: The roots of culture (pp. 129-154). London: Academic Press.

LundBerg, A. (2002). Social influences on the behaviour of laying hens. PhD thesis, Swedish University of Agricultural Sciences.

McBride, G., PARER, I. P., \& Foenander, F. (1969). The social organisation and behaviour of the feral domestic fowl. Animal Behaviour Monographs, 2, 127-181.

MCCABE, B. J., HoRn, G., \& KENDRICK, K. M. (2001). GABA, taurine and learning: Release of amino acids from slices of chick brain following filial imprinting. Neuroscience, 105, 317-324.

MCQuOID, L. M., \& GALEF, B. G., JR. (1992). Social influences on feeding site selection by Burmese fowl (Gallus gallus). Journal of Comparative Psychology, 106, 137-141.

MCQuoID, L. M., \& GALEF, B. G., JR. (1993). Social stimuli influencing feeding behaviour of Burmese fowl: A video analysis. Animal Behaviour, 46, 13-22.

MCQuoid, L. M., \& GALEF, B. G., JR. (1994). Effects of access to food during training on social learning by Burmese red junglefowl. Animal Behaviour, 48, 737-739.

MenCH, J., \& KeELING, L. J. (2001). The social behaviour of domestic birds. In L. J. Keeling \& H. W. Gonyou (Eds.), Social behaviour in farm animals (pp. 177-209). Wallingford, U.K.: CABI Publishing.

Moffatt, C. A., \& Hogan, J. A. (1992). Ontogeny of chick responses to maternal food calls in the Burmese red junglefowl. Animal Behaviour, 46, 13-22.

NiCOL, C. J. (1995). The social transmission of information and behaviour. Applied Animal Behaviour Science, 44, 79-98.

Nicol, C. J., \& PoPE, S. J. (1992). Effects of social learning on the acquisition of discriminatory keypecking in hens. Bulletin of the Psychonomic Society, 30, 293-296. 
Nicol, C. J., \& Pope, S. J. (1993). Food deprivation during observation reduces social learning in hens. Animal Behaviour, 45, 193-196.

Nicol, C. J., \& POPE, S. J. (1994). Social learning in small flocks of laying hens. Animal Behaviour, 47, 1289-1296.

NiCOL, C. J., \& POPE, S. J. (1996). The maternal feeding display of domestic hens is sensitive to perceived chick error. Animal Behaviour, 52, 767-774.

Nicol, C. J., \& Pope, S. J. (1999). The effects of demonstrator social status and prior foraging success on social learning in domestic hens. Animal Behaviour, 57, 163-171.

Patterson-Kane, E., Nicol, C. J., Foster, T. M., \& Temple, W. (1997). Limited perception of video images by domestic hens. Animal Behaviour, 53, 951-963.

PfefFer, K., FritZ, J., \& Kotrschal, K. (2002). Hormonal correlates of being an innovative greylag goose Anser anser. Animal Behaviour, 63, 687-695.

READER, S. M., \& LALAND, K. N. (1999). Foraging innovation in the guppy. Animal Behaviour, 57, 331-340.

SAVORY, C. J. (1995). Feather pecking and cannibalism. World's Poultry Science Journal, 51, 215-219.

SHERRY, D. F. (1977). Parental food-calling and the role of the young in the Burmese red junglefowl (Gallus gallus spadiceus). Animal Behaviour, 25, 594-601.

Sherwin, C. M., Heyes, C. M., \& Nicol, C. J. (2002). Social learning influences the preferences of domestic hens for novel food. Animal Behaviour, 63, 933-942.

Sherwin, C. M., HeYes, C. M., \& NiCOL, C. J. (2004). The role of visual and auditory cues in the social transmission of feather pecking in domestic fowl. Manuscript in preparation.
Stokes, A. W. (1971). Parental and courtship feeding in red junglefowl. Auk, 88, 21-29.

Suboski, M. D., \& Bartashunas, C. (1984). Mechanisms for social transmission of pecking preferences to neonatal chicks. Journal of Experimental Psychology: Animal Behavior Processes, 10, 182-194. Swaney, W., Kendal, J., Capon, H., Brown, C., \& Laland, K. N. (2001). Familiarity facilitates social learning of foraging behaviour in the guppy. Animal Behaviour, 62, 591-598.

VALLORTIGARA,G., \& ANDREW, R. J. (1991). Lateralization of response by chicks to change in a model partner. Animal Behaviour, 41, 187-194.

VAllortigara, G., Andrew, R. J., Sertori, L., \& Regolin, L. (1997). Sharply timed behavioral changes during the first 5 weeks of life in the domestic chick (Gallus gallus). Bird Behavior, 12, 29-40.

Wauters, A. M., Richard-Yris, M. A., Pierre, J. S., Lunel, C., \& RiCHARD, J. P. (1999). Influence of chicks and food quality on food calling in broody domestic hens. Behaviour, 136, 919-933.

Wood-Gush, D. G. M. (1971). The behaviour of the domestic fowl. London: Heinemann.

Wood-Gush, D. G. M., \& Duncan, I. J. H. (1976). Some behavioural observations on domestic fowl in the wild. Applied Animal Ethology, 2, 255-260.

Zeltner, E., Klein, T., \& Huber-Eicher, B. (2000). Is there social transmission of feather pecking in groups of laying hen chicks? Animal Behaviour, 60, 211-216.

Zentall, T. R., \& Galef, B. G., JR. (1988). Social learning: Psychological and biological perspectives. Hillsdale, NJ: Erlbaum.

Zimme Rman, P. H., \& Koene, P. (1998). The effect of frustrative nonreward on vocalisations and behaviour in the laying hen, Gallus gallus domesticus. Behavioural Processes, 44, 73-79. 